\title{
Prediction of the solubility of aromatic components of wine in carbon dioxide
}

\author{
Marta Vázquez da Silva, Domingos Barbosa* \\ Departamento de Engenharia Química, Faculdade de Engenharia da Universidade do Porto, Pólo FEUP do Centro de Biotecnologia e \\ Química Fina, Rua Dr. Roberto Frias, 4200-465 Porto, Portugal
}

Received 11 March 2003; received in revised form 10 September 2003; accepted 30 September 2003

\begin{abstract}
The possibility of using group contribution methods to predict the solubility of the most important families of aromatic compounds of wine-alcohols, esters and aldehydes-in carbon dioxide $\left(\mathrm{CO}_{2}\right)$ is analyzed in this work by comparing the results obtained with three different predictive methods, which couple equations of state and mixing rules based on the concept of the excess Gibbs free energy. The methods studied are the Predictive Soave-Redlich-Kwong (PSRK), the Linear Combination of the Vidal and Michelsen mixing rules (LCVM) and the Wong-Sandler mixing rule (WS). In all these models the excess Gibbs free energy is calculated by the UNIFAC method. For the WS mixing rule, interaction parameters between the groups $\mathrm{CO}_{2} / \mathrm{CH}_{2}$, $\mathrm{CO}_{2} / \mathrm{OH}, \mathrm{CO}_{2} / \mathrm{CCOO}$ and $\mathrm{CO}_{2} / \mathrm{CHO}$ are obtained. For the LCVM mixing rule, interaction parameters are calculated for the groups $\mathrm{CO}_{2} / \mathrm{CHO}$, and revised values for the groups $\mathrm{CO}_{2} / \mathrm{OH}$ are suggested. Finally, for the PSRK mixing rule, revised values are proposed for the interaction parameters between the groups $\mathrm{CO}_{2} / \mathrm{OH}$ and $\mathrm{CO}_{2} / \mathrm{CHO}$. The results of this work show that the PSRK is the method that best predicts the phase equilibria for the systems studied, with a quadratic mean deviation lower than $5.5 \%$.
\end{abstract}

(C) 2003 Elsevier B.V. All rights reserved.

Keywords: Phase equilibria; Prediction; Mixing rules; Wine; Carbon dioxide

\section{Introduction}

Wine is one of the most complex alcoholic beverages, mainly due to the presence of numerous volatile organic compounds, of which more than 800 have already been identified [1,2]. These compounds belong to a wide variety of chemical families, namely, acids, esters, alcohols, aldehydes, lactones, terpenes,

\footnotetext{
* Corresponding author. Tel.: +351-22-508-1660; fax: $+351-22-508-1449$.

E-mail address: dbarbosa@fe.up.pt (D. Barbosa).
}

nor-isoprenoids, pyrazines, and many others. The characteristic bouquet of a wine is largely the balance of the contribution of these different compounds and not the result of an individual impact. Therefore, it seems clear that the implementation of a dealcoholization process, in which the main goal is to remove the ethanol while preserving the organoleptic properties of the wine, is a very complex and challenging problem.

In recent years, supercritical fluid extraction with carbon dioxide has been suggested as a promising alternative to other conventional dealcoholization 


\begin{tabular}{|c|c|}
\hline \multicolumn{2}{|c|}{ Nomenclature } \\
\hline$a(T)$ & $\begin{array}{l}\text { equation of state attractive } \\
\text { parameter }\left(\mathrm{Pa} \mathrm{m}^{6} \mathrm{~mol}^{-2}\right)\end{array}$ \\
\hline$a_{\mathrm{c}, i}$ & $\begin{array}{l}\text { equation of state attractive } \\
\text { parameter for component } i \text { at the } \\
\text { critical conditions }\left(\mathrm{Pa} \mathrm{m}^{6} \mathrm{~mol}^{-2}\right)\end{array}$ \\
\hline$a_{i}(T)$ & $\begin{array}{l}\text { equation of state attractive } \\
\text { parameter for component } \\
i\left(\mathrm{~Pa} \mathrm{~m}^{6} \mathrm{~mol}^{-2}\right)\end{array}$ \\
\hline$A_{\mathrm{km}}$ & $\begin{array}{l}\text { UNIFAC group interaction } \\
\text { parameter }(\mathrm{K})\end{array}$ \\
\hline$b$ & $\begin{array}{l}\text { equation of state parameter } \\
\left(\mathrm{m}^{3} \mathrm{~mol}^{-1}\right)\end{array}$ \\
\hline$B(T)$ & $\begin{array}{l}\text { second virial coefficient } \\
\left(\mathrm{m}^{3} \mathrm{~mol}^{-1}\right)\end{array}$ \\
\hline$b_{i}$ & $\begin{array}{l}\text { equation of state parameter for } \\
\text { component } i\left(\mathrm{~m}^{3} \mathrm{~mol}^{-1}\right)\end{array}$ \\
\hline$B_{i j}(T)$ & $\begin{array}{l}\text { cross virial coefficient } \\
\left(\mathrm{m}^{3} \mathrm{~mol}^{-1}\right)\end{array}$ \\
\hline$B_{\mathrm{km}}$ & $\begin{array}{l}\text { UNIFAC group interaction } \\
\text { parameter }\end{array}$ \\
\hline$c_{1}, c_{2}$ & EOS characteristic constants \\
\hline$C_{1}, C_{2}, C_{3}$ & $\begin{array}{l}\text { Mathias-Copeman equation } \\
\text { constants }\end{array}$ \\
\hline$C_{\mathrm{km}}$ & $\begin{array}{l}\text { UNIFAC group interaction } \\
\text { parameter }\left(\mathrm{K}^{-1}\right)\end{array}$ \\
\hline $\begin{array}{l}C_{1, \mathrm{LCVM}} \\
\quad C_{2, \mathrm{LCVM}}\end{array}$ & LCVM mixing rule constants \\
\hline$C_{\mathrm{PSRK}}$ & PSRK mixing rule constant \\
\hline$C_{\mathrm{WS}}$ & WS mixing rule constant \\
\hline FOB & objective function \\
\hline$G^{\mathrm{E}}$ & $\begin{array}{l}\text { excess molar Gibbs free } \\
\text { energy }\left(\mathrm{J} \mathrm{mol}^{-1}\right)\end{array}$ \\
\hline$G_{0}^{\mathrm{E}}$ & $\begin{array}{l}\text { excess molar Gibbs free energy at } \\
\text { low pressure }\left(\mathrm{J} \mathrm{mol}^{-1}\right)\end{array}$ \\
\hline$k_{i j}$ & $\begin{array}{l}\text { molecular interaction parameter of } \\
\text { the WS mixing rule }\end{array}$ \\
\hline $\begin{array}{l}m_{0, i}, m_{1, i} \\
\quad m_{i}\end{array}$ & Stryjek-Vera equation constants \\
\hline $\mathrm{nc}$ & number of components \\
\hline NRES & number of results \\
\hline$p$ & Pressure $(\mathrm{Pa})$ \\
\hline$P_{\mathrm{c}, i}$ & $\begin{array}{l}\text { critical pressure of component } \\
i(\mathrm{~Pa})\end{array}$ \\
\hline$Q_{\mathrm{k}}$ & $\begin{array}{l}\text { UNIFAC area parameter for } \\
\text { the functional group } \mathrm{k} \text {. }\end{array}$ \\
\hline
\end{tabular}

\begin{tabular}{|c|c|}
\hline$R$ & $\begin{array}{l}\text { ideal gas constant } \\
\left(\mathrm{Pa} \mathrm{m}^{3} \mathrm{~mol}^{-1} \mathrm{~K}^{-1}\right)\end{array}$ \\
\hline$R_{\mathrm{k}}$ & $\begin{array}{l}\text { UNIFAC volume parameter for } \\
\text { the functional group } \mathrm{k}\end{array}$ \\
\hline$T$ & temperature $(\mathrm{K})$ \\
\hline$T_{\mathrm{c}, i}$ & $\begin{array}{l}\text { critical temperature of } \\
\text { component } i(\mathrm{~K})\end{array}$ \\
\hline$T_{\mathrm{r}, i}$ & $\begin{array}{l}\text { reduced temperature of } \\
\text { component } i\left(T / T_{\mathrm{c}, i}\right)\end{array}$ \\
\hline$V$ & molar volume $\left(\mathrm{m}^{3} \mathrm{~mol}^{-1}\right)$ \\
\hline$x_{\mathrm{CALC}, i}$ & $\begin{array}{l}\text { calculated value of liquid phase } \\
\text { mole fraction }\end{array}$ \\
\hline$x_{\mathrm{CO}_{2}}$ & $\begin{array}{l}\text { mole fraction of } \mathrm{CO}_{2} \text { in the } \\
\text { liquid phase }\end{array}$ \\
\hline$x_{\mathrm{EXP}, i}$ & $\begin{array}{l}\text { experimental value of liquid } \\
\text { phase mole fraction }\end{array}$ \\
\hline$x_{i}$ & component $i$ mole fraction \\
\hline$y_{\mathrm{CALC}, i}$ & $\begin{array}{l}\text { calculated value of vapor } \\
\text { phase mole fraction }\end{array}$ \\
\hline$y_{\mathrm{CO}_{2}}$ & $\begin{array}{l}\text { mole fraction of } \mathrm{CO}_{2} \text { in } \\
\text { the vapor phase }\end{array}$ \\
\hline$y_{\mathrm{EXP}, i}$ & $\begin{array}{l}\text { experimental value of vapor } \\
\text { phase mole fraction }\end{array}$ \\
\hline \multicolumn{2}{|c|}{ Greek letters } \\
\hline$\alpha$ & $\begin{array}{l}\text { dimensionless equation of } \\
\text { state parameter, } \alpha=a(T) /(b R T)\end{array}$ \\
\hline$\alpha_{i}$ & $\begin{array}{l}\text { dimensionless equation of state } \\
\text { parameter for component } i \\
\alpha_{i}=a_{i}(T) /\left(b_{i} R T\right)\end{array}$ \\
\hline$\varepsilon$ & mean quadratic deviation \\
\hline$\omega_{i}$ & acentric factor \\
\hline$\psi_{\mathrm{km}}$ & UNIFAC interaction parameter \\
\hline \multicolumn{2}{|c|}{ Abbreviations } \\
\hline EOS & equation of state \\
\hline $\mathrm{EOS} / G^{\mathrm{E}}$ & $\begin{array}{l}\text { equation of state and excess } \\
\text { Gibbs free energy models }\end{array}$ \\
\hline LCVM & $\begin{array}{l}\text { linear combination of the Vidal } \\
\text { and Michelsen mixing rules }\end{array}$ \\
\hline NRTL & non-random two liquids \\
\hline PR & Peng-Robinson \\
\hline PRSV & Peng-Robinson-Stryjek-Vera \\
\hline PSRK & $\begin{array}{l}\text { Predictive Soave-Redlich- } \\
\text { Kwong }\end{array}$ \\
\hline SRK & Soave-Redlich-Kwong. \\
\hline
\end{tabular}




$\begin{array}{ll}\text { UNIFAC } & \begin{array}{l}\text { UNIQUAC functional group } \\ \text { activity coefficients }\end{array} \\ \text { UNIQUAC } & \text { Universal QuasiChemical } \\ \text { WS } & \text { Wong-Sandler }\end{array}$

techniques [3-5], such as: distillation [6-9], evaporation [10-12], osmosis [6,13-17] and solvent extraction [18]. The design of the dealcoholization process by supercritical fluid extraction with $\mathrm{CO}_{2}$ requires information on the solubility of the aromatic compounds of wine in carbon dioxide. However, the experimental measurement of phase equilibria is a difficult, time consuming, and expensive process, which, for complex mixtures such as wine, becomes an endless task. Thus, the development of predictive methods, which allow overcoming the lack of experimental data, is of the uppermost importance for the design of this type of processes. These predictive methods are less precise than the alternative correlation methods, however, the correlation methods have the disadvantage of needing experimental data to be applied.

The prediction of phase equilibria at high pressures is commonly accomplished by coupling cubic equations of state (EOS), such as the Soave-RedlichKwong (SRK) and Peng-Robinson (PR), with mixing rules based on the concept of the excess Gibbs free energy $\left(G^{\mathrm{E}}\right)$, as was first suggested by Huron and Vidal [19]. These models are usually referred to as EOS $/ G^{\mathrm{E}}$ models. The $G^{\mathrm{E}}$ is typically obtained by using expressions of the excess Gibbs free energy developed for liquid solutions at moderate pressures, such as the Wilson, NRTL and UNIQUAC equations. If the interaction parameters for the $G^{\mathrm{E}}$ model are available, the $\mathrm{EOS} / G^{\mathrm{E}}$ models allow the prediction of phase equilibria at high pressures by using parameters obtained from data at low pressures. The EOS $/ G^{\mathrm{E}}$ models can be made totally predictive if the excess Gibbs free energy is calculated by a group contribution method, such as the UNIFAC.

In this work, three EOS $/ G^{\mathrm{E}}$ methods, based in three different mixing rules, are studied, and their capability for predicting the solubility of the most important families of aromatic compounds of wine in $\mathrm{CO}_{2}$ is analyzed. These methods are the PSRK [20], which has been one of the most extensively used and for which there are a large number of interaction parameters published, the LCVM [21], that has been suggested to give very good results for polar and asymmetric systems, and for which there are also some parameters published, and the WS mixing rule [22,23], which has the advantage of being theoretically consistent, because it gives rise to a quadratic dependence on composition for the second virial coefficient, but for which there are no parameters published for the group $\mathrm{CO}_{2}$.

These methods can be used to predict phase equilibria at high pressures using the UNIFAC parameters obtained at low and moderate pressures for vapor-liquid equilibrium. At most, there is only need to extend the existing table of parameters to account for the new groups introduced, such as $\mathrm{CO}_{2}$ and other gases. This is, by far, the most important feature of these models.

\section{PSRK mixing rule}

The PSRK [20] has been one of the most extensively used methods to predict phase equilibria at high pressures, which associates an equation of state with a mixing rule based in an excess Gibbs free energy model. This method uses the SRK-EOS

$P=\frac{R T}{V-b}-\frac{a(T)}{V(V+b)}$

The $a$ and $b$ parameters of the EOS for pure component i (i.e. $a_{i}$ and $b_{i}$ ) are given by the following equations

$a_{i}(T)=a_{\mathrm{c}, i} f\left(T, T_{\mathrm{c}, i}, \omega_{i}\right)$

and

$b_{i}=0.08664 \frac{R T_{\mathrm{c}, i}}{P_{\mathrm{c}, i}}$

where

$a_{\mathrm{c}, i}=0.42747 \frac{R^{2} T_{\mathrm{c}, i}^{2}}{P_{\mathrm{c}, i}}$

The subscript $\mathrm{c}$ indicates that the properties are evaluated at the critical point. For non-polar substances, $f\left(T, T_{\mathrm{c}, i}, \omega_{i}\right)$ is given by

$$
\begin{aligned}
f\left(T, T_{\mathrm{c}, i}, \omega_{i}\right)= & {\left[1+\left(0.480+1.574 \omega_{i}\right.\right.} \\
& \left.\left.-0.176 \omega_{i}^{2}\right)\left(1-\sqrt{T_{\mathrm{r}, i}}\right)\right]^{2}
\end{aligned}
$$

where $T_{\mathrm{r}, i}$ is the reduced temperature of pure component $i$. The critical properties and the acentric factor 
for the components used in this study are given in Appendix A (Table A.1).

For polar substances, and in order to improve the quality of the prediction, the function $f\left(T, T_{\mathrm{c}, i}, \omega_{i}\right)$ is obtained by the Mathias-Copeman method [24], which means that $f\left(T, T_{\mathrm{c}, i}, \omega_{i}\right)=f\left(T, T_{\mathrm{c}, i}\right)$, where
$[20,25]$ calculated the UNIFAC interaction parameters for mixtures containing gases, such as $\mathrm{N}_{2}, \mathrm{H}_{2}, \mathrm{H}_{2} \mathrm{~S}$, $\mathrm{CH}_{4}, \mathrm{CO}$ and $\mathrm{CO}_{2}$.

The data for the UNIFAC method, necessary to study the applicability of the PSRK model, are presented in Appendix B (Tables B.1 and B.2).

$f\left(T, T_{\mathrm{c}, i}\right)= \begin{cases}{\left[1+C_{1}\left(1-\sqrt{T_{\mathrm{r}, i}}\right)+C_{2}\left(1-\sqrt{T_{\mathrm{r}, i}}\right)^{2}+C_{3}\left(1-\sqrt{T_{\mathrm{r}, i}}\right)^{3}\right]^{2},} & T_{\mathrm{r}, i} \leq 1 \\ {\left[1+C_{1}\left(1-\sqrt{T_{\mathrm{r}, i}}\right)\right]^{2},} & T_{\mathrm{r}, i}>1\end{cases}$

The constants $C_{1}, C_{2}$ and $C_{3}$ are adjustable parameters obtained by fitting the EOS to pure component vapor pressure data. The values of these constants, for the components used in this work, are summarized in Appendix A (Table A.2).

When applied to mixtures, the PSRK model calculates the parameter $b$ as a linear combination of the pure component parameters, $b_{i}$

$b=\sum_{i=1}^{\mathrm{nc}} x_{i} b_{i}$

and the parameter $a$ is obtained by calculating the dimensionless quantity $\alpha$, defined as $\alpha=a(T) /(b R T)$, for mixtures, and $\alpha_{i}=a_{i}(T) /\left(b_{i} R T\right)$, for pure component $i$. According to the PSRK model, $\alpha$ is given by

$\alpha=\frac{1}{C_{\mathrm{PSRK}}}\left[\frac{G_{0}^{\mathrm{E}}}{R T}+\sum_{i=1}^{\mathrm{nc}} x_{i} \ln \frac{b}{b_{i}}\right]+\sum_{i=1}^{\mathrm{nc}} x_{i} \alpha_{i}$

where $C_{\text {PSRK }}$ is a constant that takes the value of -0.647 , and $G_{0}^{\mathrm{E}}$ is the excess molar Gibbs free energy obtained by a low pressure solution model. In order to use the PSRK mixing rule in a totally predictive form, the Gibbs energy must be calculated by a group contribution method, such as UNIFAC.

In the PSRK model, the UNIFAC interaction parameters are assumed to be temperature dependent, and the parameter $\psi_{\mathrm{km}}$ of the UNIFAC method is calculated by the expression

$\psi_{\mathrm{km}}=\exp \left(-\frac{A_{\mathrm{km}}+B_{\mathrm{km}} T+C_{\mathrm{km}} T^{2}}{T}\right)$

However, for the UNIFAC main groups up to number 44 , the parameters for the original UNIFAC method published for vapor-liquid equilibria are used by the PSRK method [20,25-27] and, therefore, the constants $B_{\mathrm{km}}$ and $C_{\mathrm{km}}$ are equal to zero. To extend the predictive capabilities of the PSRK model, some authors

\section{LCVM mixing rule}

Another common method for the prediction of phase equilibria at high pressure is based on the LCVM mixing rule [21], which is a linear combination of the Vidal [28] and Michelsen [29] mixing rules. The LCVM mixing rule is usually used associated with the PR-EOS

$P=\frac{R T}{V-b}-\frac{a(T)}{V(V+b)+b(V-b)}$

For pure component $i$, the parameter $b$ of the PR-EOS is given by

$b_{i}=0.07780 \frac{R T_{\mathrm{c}, i}}{P_{\mathrm{c}, i}}$

and the parameter $a(T)$ is calculated by

$a_{i}(T)=a_{\mathrm{c}, i} f\left(T, T_{\mathrm{c}, i}\right)$

with

$a_{\mathrm{c}, i}=0.45724 \frac{R^{2} T_{\mathrm{c}, i}^{2}}{P_{\mathrm{c}, i}}$

being $f\left(T, T_{\mathrm{c}, i}\right)$ obtained by the method of MathiasCopeman (Eq. (6)). In Appendix A (Table A.2), the Mathias-Copeman constants are listed for the PR-EOS.

For the LCVM model, the parameters $b$ and $\alpha$ of the mixture are obtained by Eqs. (7) and (14), respectively

$$
\alpha=\frac{1}{C_{1, \mathrm{LCVM}}} \frac{G_{0}^{\mathrm{E}}}{R T}+C_{2, \mathrm{LCVM}} \sum_{i=1}^{\mathrm{nc}} x_{i} \ln \frac{b}{b_{i}}+\sum_{i=1}^{\mathrm{nc}} x_{i} \alpha_{i}
$$

The constants $C_{1, \mathrm{LCVM}}$ and $C_{2, \mathrm{LCVM}}$ take the values of -0.558 and -1.213 , respectively. 
The LCVM mixing rule has also been applied with the original UNIFAC group contribution model, using the published interaction parameters for vapor-liquid equilibrium and the new parameters obtained for gases, such as $\mathrm{CO}_{2}$ [30].

The LCVM model considers also that the UNIFAC interaction parameters are temperature dependent, and that the UNIFAC parameter $\psi_{\mathrm{km}}$ is given by Eq. (15)

$\psi_{\mathrm{km}}=\exp \left(-\frac{A_{\mathrm{km}}+B_{\mathrm{km}}(T-298.15)}{T}\right)$

To study the applicability of the LCVM model to predict the solubility for aromatic components of wine in $\mathrm{CO}_{2}$, the interaction parameters for the groups $\mathrm{CO}_{2} / \mathrm{CHO}$ had to be determined, because no published values could be found in the literature. All other parameters needed for using the UNIFAC model associated with the LCVM mixing rule can be found in Appendix B (Tables B.1 and B.3).

\section{WS mixing rule}

The PSRK and LCVM models do not give rise to a quadratic dependence on composition for the second virial coefficient, and therefore are not theoretically consistent. To overcome this inconsistency, Wong and Sandler [22] proposed a new mixing rule that predicts the correct composition dependence for the second virial coefficient. Indeed, expanding a cubic EOS in a Taylor's series, the following relationship can be found between the second virial coefficient, $B(T)$, and the parameters $\mathrm{a}$ and $\mathrm{b}$ of the cubic EOS [31],

$B(T)=b-\frac{a(T)}{R T}$

Since $B(T)$ has a quadratic dependence on composition, it can be written that

$$
B(T)=b-\frac{a(T)}{R T}=\sum_{i=1}^{\mathrm{nc}} \sum_{j=1}^{\mathrm{nc}} x_{i} x_{j}\left(b-\frac{a(T)}{R T}\right)_{i j}
$$

The value of $(b-(a(T) /(R T)))_{i j}$, which is the cross virial coefficient $B_{i j}$, is only a function of temperature, and cannot be composition dependent. For the calculation of the cross virial coefficient, Wong and Sandler proposed the following combining rule

$$
\begin{aligned}
B_{i j}(T) & =\left(b-\frac{a(T)}{R T}\right)_{i j} \\
& =\frac{\left(b_{i}-\frac{a_{i}(T)}{R T}\right)+\left(b_{j}-\frac{a_{j}(T)}{R T}\right)}{2}\left(1-k_{i j}\right)
\end{aligned}
$$

where $k_{i j}$ is a binary interaction parameter, independent of composition. For pure component $i$, this interaction parameter takes the value of zero (i.e. $k_{i i}=0$ ).

To calculate the parameter $\alpha$ of a mixture, Wong and Sandler proposed the following mixing rule

$\alpha=\frac{G_{0}^{\mathrm{E}}}{R T C_{\mathrm{WS}}}+\sum_{i=1}^{\mathrm{nc}} x_{i} \alpha_{i}$

which, combined with Eqs. (17) and (18), gives rise to the following expression for obtaining the parameter $b$ of the mixture

$$
b=\frac{\sum_{j=1}^{\mathrm{nc}} \sum_{i=1}^{\mathrm{nc}} x_{j} x_{i}\left(b-\frac{a(T)}{R T}\right)_{i j}}{1-\frac{G_{0}^{\mathrm{E}}}{R T C_{\mathrm{WS}}}-\sum_{i=1}^{\mathrm{nc}} x_{i} \alpha_{i}}
$$

Eqs. (19) and (20) completely define the WS mixing rule. The value of the constant $C_{\mathrm{WS}}$ depends on the equation of state used, taking the values of -0.693 and -0.623 , for the SRK and PR equations of state, respectively.

In its original form, the WS mixing rule cannot be used as a totally predictive method because the value of the molecular interaction parameter $k_{i j}$ must be known, which means that experimental phase equilibrium data must be available. To overcome this difficulty, Coutsikos et al. [23] proposed the evaluation of the interaction parameter $k_{i j}$ by setting equal the values of the excess Gibbs free energy calculated from the equation of state $\left(G_{\mathrm{EOS}}^{\mathrm{E}}\right)$ and the value of $G^{\mathrm{E}}$ obtained by a solution model $\left(G_{0}^{\mathrm{E}}\right)$ for fixed values of composition and temperature (i.e. $G_{\mathrm{EOS}}^{\mathrm{E}}=G_{0}^{\mathrm{E}}$, for fixed values of $x_{i}$ and $T$ ). For a binary mixture, it can be shown that $k_{12}$ is given by

$$
k_{12}=\frac{x_{1} B_{11}(T)+x_{2} B_{22}(T)-(1-\alpha) \exp \left[x_{1} \ln b_{1}+x_{2} \ln b_{2}+q(\alpha)-x_{1} q\left(\alpha_{1}\right)-x_{2} q\left(\alpha_{2}\right)\right]}{x_{1} x_{2}\left(B_{11}(T)+B_{22}(T)\right)}
$$


where

$q(\alpha)=-\ln (u-1)-\frac{\alpha}{c_{1}-c_{2}} \ln \frac{u+c_{1}}{u+c_{2}}-C_{\mathrm{WS}} \alpha$

and

$u=\frac{\left(\alpha-c_{1}-c_{2}\right)-\sqrt{\begin{array}{l}\alpha^{2}-2 \alpha\left(2+c_{1}+c_{2}\right) \\ +\left(c_{1}-c_{2}\right)^{2}\end{array}}}{2}$

The constants $c_{1}$ and $c_{2}$ are characteristic of the EOS being considered, taking the values of 1 and 0 , for the SRK-EOS, and $1+\sqrt{2}$ and $1-\sqrt{2}$, for the PR-EOS, respectively, and $\alpha$ is given by Eq. (19). In this work, the value of $k_{12}$ was calculated for an equimolar mixture (i.e. $x_{1}=x_{2}=0.5$ ) at a temperature of $273.15 \mathrm{~K}$. As suggested by Wong and Sandler [22], the WS mixing rule was applied coupled with the PR-EOS according to the modification proposed by Stryjek and Vera [32] (i.e. PRSV-EOS). Therefore, the parameter $a_{i}$ must now be obtained by the expression

$a_{i}(T)=a_{\mathrm{c}, i} f\left(T, T_{\mathrm{c}, i}, \omega_{i}\right)$

where

$f\left(T, T_{\mathrm{c}, i}, \omega_{i}\right)=\left[1+m_{i}\left(1-\sqrt{T_{\mathrm{r}, i}}\right)\right]^{2}$

with

$m_{i}=m_{0, i}+m_{1, i}\left(1+\sqrt{T_{\mathrm{r}, i}}\right)\left(0.7-T_{\mathrm{r}, i}\right)$

and

$$
\begin{aligned}
m_{0, i}= & 0.378893+1.4897153 \omega_{i}-0.17131848 \omega_{i}^{2} \\
& +0.0196554 \omega_{i}^{3}
\end{aligned}
$$

with $a_{\mathrm{c}, i}$ given by Eq. (13). The parameter $m_{1, i}$ is an adjustable parameter characteristic of each component whose value, for the substances used in this study, are summarized in Appendix A (Table A.2). This parameter is obtained by fitting the PRSV-EOS to vapor pressure data for pure components.

In this work, to study the applicability of the WS mixing rule, the modified UNIFAC model [33-35] is used to calculate the excess Gibbs energy, with the parameters given in Appendix B (Table B.4).

\section{Prediction of phase equilibria}

To study the capability of the WS mixing rule to predict the solubility of aromatic compounds of wine in $\mathrm{CO}_{2}$, it was necessary to calculate the interaction parameters between the characteristic group of each family to be studied and the group $\mathrm{CO}_{2}$. The optimization procedure to obtain these interaction parameters used the method of Roth-Meyer [36], based in the second order Levenberg-Marquardt algorithm [37], to minimize the objective function,

$\mathrm{FOB}=\frac{\begin{array}{c}\sum_{i=1}^{\mathrm{NRES}}\left(x_{\mathrm{EXP}, i}-x_{\mathrm{CALC}, i}\right)^{2} \\ +\sum_{i=1}^{\mathrm{NRES}}\left(y_{\mathrm{EXP}, i}-y_{\mathrm{CALC}, i}\right)^{2}\end{array}}{2 \mathrm{NRES}}$

from which the following expression of the mean quadratic deviation, $\varepsilon$, is obtained

$\varepsilon=\sqrt{\frac{\begin{array}{c}\sum_{i=1}^{\mathrm{NRES}}\left[\left(x_{\mathrm{EXP}, i}-x_{\mathrm{CALC}, i}\right)^{2}\right. \\ \left.+\left(y_{\mathrm{EXP}, i}-y_{\mathrm{CALC}, i}\right)^{2}\right]\end{array}}{2 \mathrm{NRES}}}$

The references for the experimental data used to obtain the interaction parameters calculated in this work are given in Table C.1. A more detailed description of the optimization procedure is given by Vázquez Silva [38].

In the following paragraphs the predictive capability of the PSRK, LCVM and WS mixing rules will be analyzed for the different families of aromatic compounds of wine considered.

\section{Systems $\mathrm{CO}_{2}$ /alkane}

Since, for the WS mixing rule, there are no published parameters for the group $\mathrm{CO}_{2}$, it was necessary to begin by obtaining the interaction parameters between the groups $\mathrm{CO}_{2} / \mathrm{CH}_{2}$, because all the compounds used in this study are formed by the characteristic group of the family being considered$\mathrm{OH}$ (alcohol), CHO (aldehyde), and CCOO (ester)— and groups $\mathrm{CH}_{2}$ (alkane).

The interaction parameters for the groups $\mathrm{CO}_{2} / \mathrm{CH}_{2}$ are given in Table 1 . These parameters were obtained by fitting 244 experimental points, covering a temperature range of $244-511 \mathrm{~K}$, pressures from 0.03 to 
Table 1

Calculated interaction parameters for the WS mixing rule

\begin{tabular}{lcccccc}
\hline Group k/group m & $A_{\mathrm{km}}(\mathrm{K})$ & $A_{\mathrm{mk}}(\mathrm{K})$ & $B_{\mathrm{km}}$ & $B_{\mathrm{mk}}$ & $C_{\mathrm{km}}\left(\mathrm{K}^{-1}\right)$ & $C_{\mathrm{mk}}\left(\mathrm{K}^{-1}\right)$ \\
\hline $\mathrm{CO}_{2} / \mathrm{CH}_{2}$ & -9.889 & 45.016 & 0.00999 & -0.49380 & $-1.000 \times 10^{-3}$ & $3.1142 \times 10^{-3}$ \\
$\mathrm{CO}_{2} / \mathrm{OH}$ & 0 & 0 & 0 & 0 & 0.669243 & 0.597693 \\
$\mathrm{CO}_{2} / \mathrm{CCOO}$ & 4.470 & -7.623 & -0.02558 & 0.19992 & -0.00398 & 0.09229 \\
$\mathrm{CO}_{2} / \mathrm{CHO}$ & 289.385 & -100.000 & 0.00180 & -0.01242 & 0.105138 & $-1.2313 \times 10^{-3}$ \\
\hline
\end{tabular}

$\mathrm{CO}_{2} /$ Propane

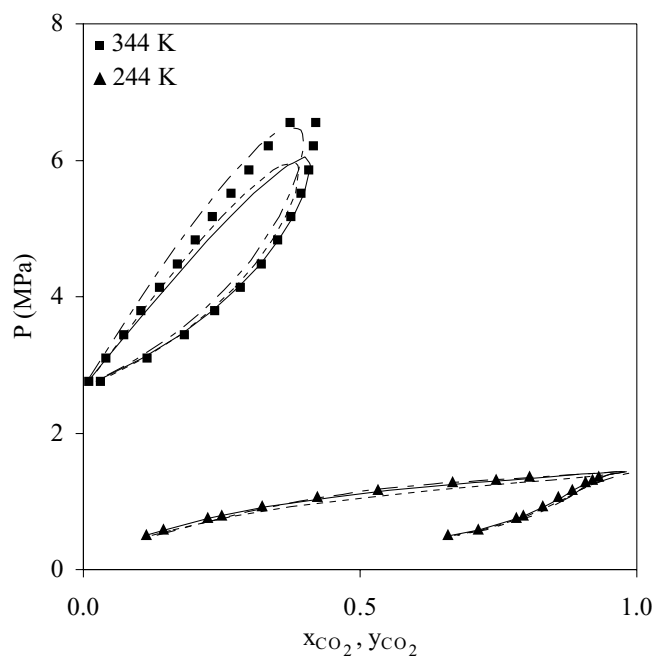

$\mathrm{CO}_{2} /$ Hexane

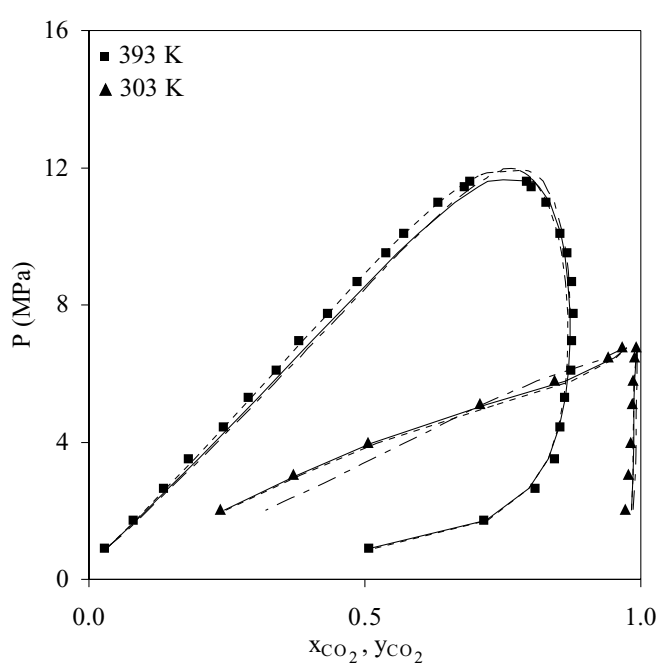

$\mathrm{CO}_{2} /$ iso-Butane

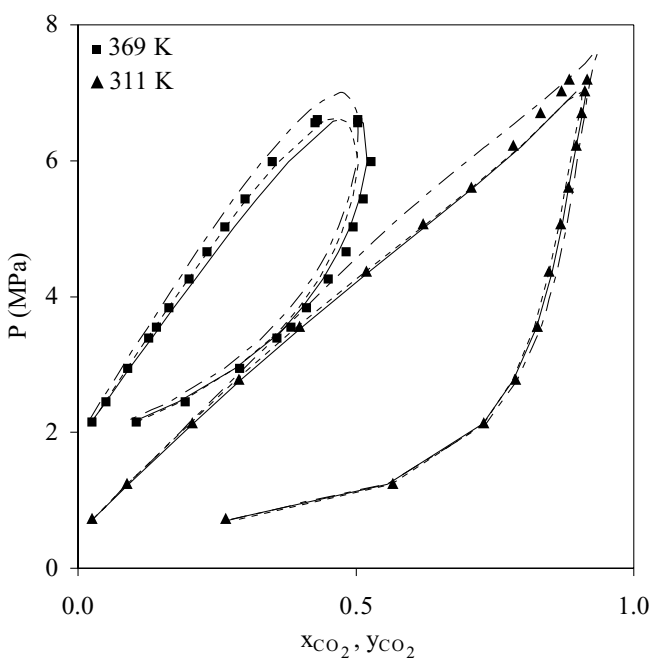

$\mathrm{CO}_{2} /$ Decane

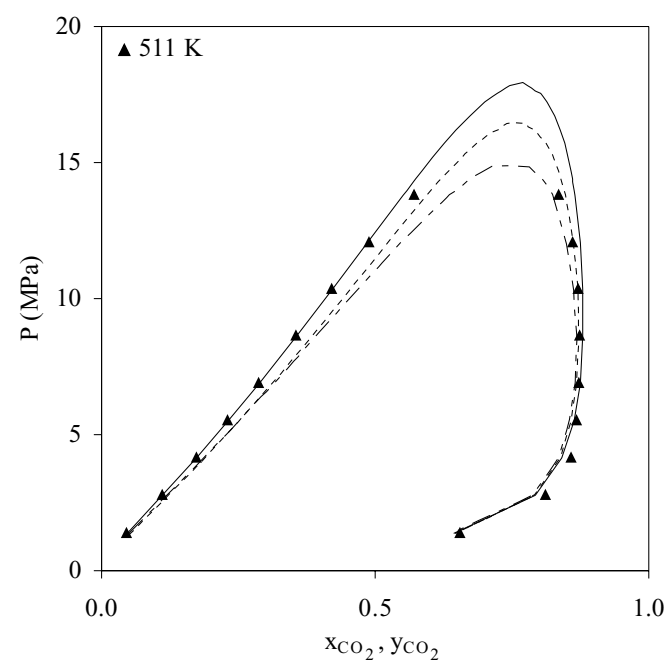

Fig. 1. PSRK (-), LCVM (---) and WS (---) predictions for systems $\mathrm{CO}_{2}$ /alkane. 
Table 2

Revised interaction parameters for the PSRK mixing rule

\begin{tabular}{lccllcc}
\hline Group k/group m & $A_{\mathrm{km}}(\mathrm{K})$ & $A_{\mathrm{mk}}(\mathrm{K})$ & $B_{\mathrm{km}}$ & $B_{\mathrm{mk}}$ & $C_{\mathrm{km}}\left(\mathrm{K}^{-1}\right)$ & $C_{\mathrm{mk}}\left(\mathrm{K}^{-1}\right)$ \\
\hline $\mathrm{CO}_{2} / \mathrm{OH}$ & 0 & 0 & 0 & 0 & 0.0017815 & 0.0035507 \\
$\mathrm{CO}_{2} / \mathrm{CHO}$ & 174.298 & -157.188 & 0 & 0 & $-2.528 \times 10^{-3}$ & $-2.247 \times 10^{-4}$ \\
\hline
\end{tabular}

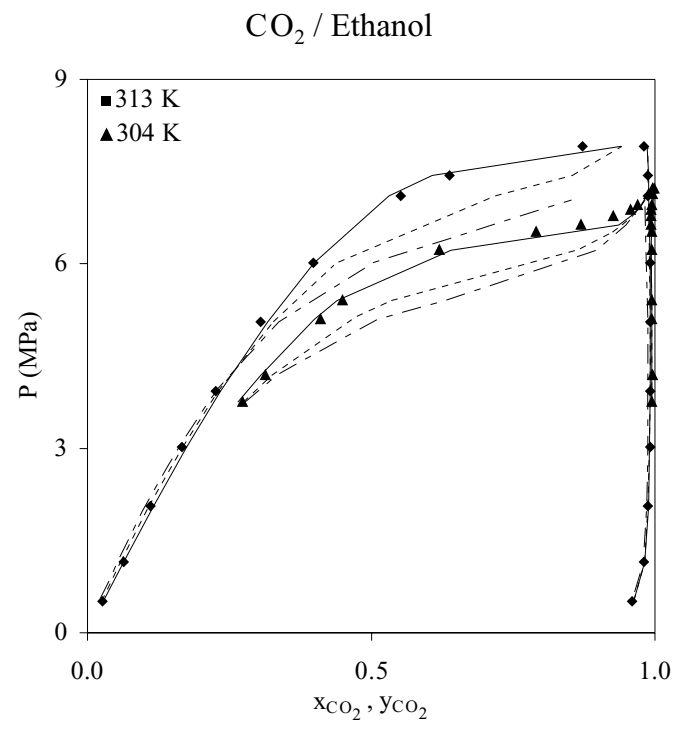

$\mathrm{CO}_{2} /$ iso-Butanol

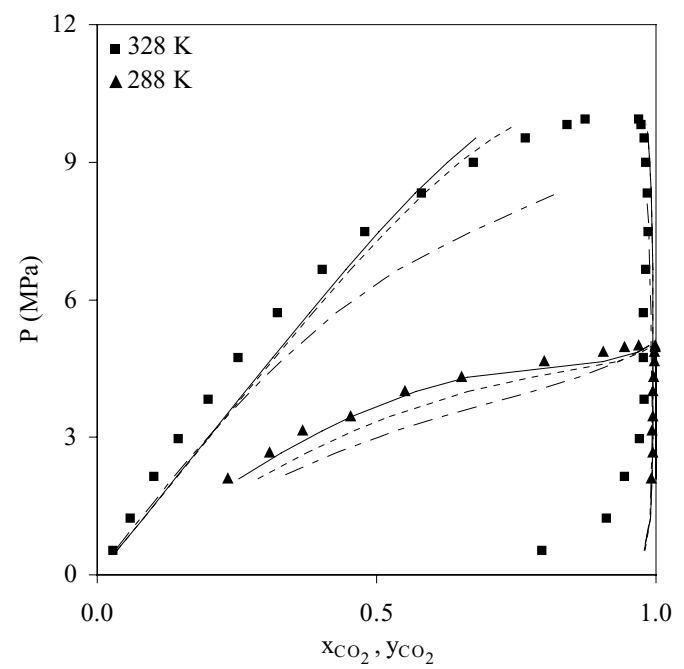

$\mathrm{CO}_{2} /$ iso-Pentanol

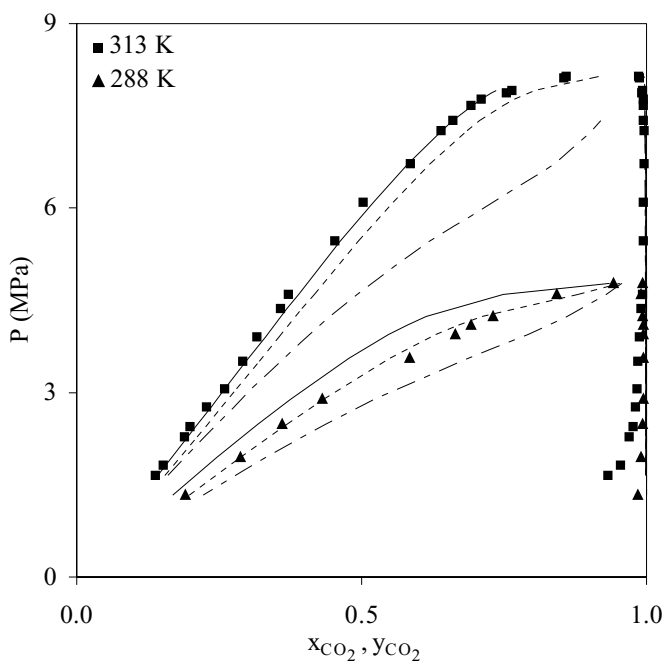

Fig. 2. PSRK (-), LCVM (---) and WS (---) predictions for systems $\mathrm{CO}_{2} /$ alcohol. 

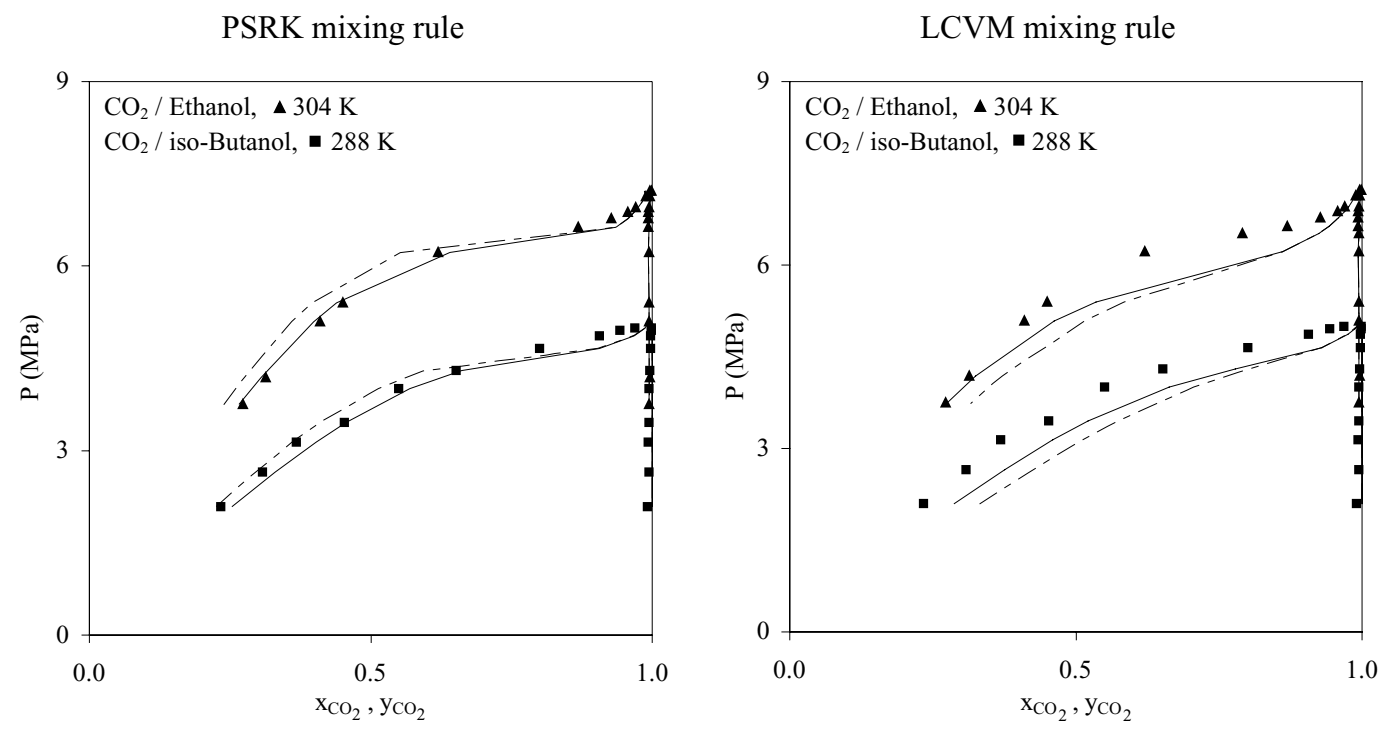

Fig. 3. Comparison between the results obtained with the published (---) and the revised (-) interaction parameters for the groups $\mathrm{CO}_{2} / \mathrm{OH}$

17.2 $\mathrm{MPa}$, and including alkanes with a number of carbon atoms between 3 and 10 .

In Fig. 1, the predictions by the PSRK, LCVM and WS models are compared for binary mixtures of propane, iso-butane, hexane and decane with carbon dioxide. An analysis of this figure shows that the WS mixing rule predicts satisfactorily the phase equilibria for the systems $\mathrm{CO}_{2}$ /propane and $\mathrm{CO}_{2} /$ iso-butane, but the quality of the prediction decreases with the increasing of the number of carbon atoms of the alkane. The PSRK and LCVM models fail to correctly predict the phase equilibria for the $\mathrm{CO}_{2} /$ propane system at high pressures and temperatures, but give better results than the WS mixing rule for the other systems studied.

The mean quadratic deviation, $\varepsilon$, for all the systems $\mathrm{CO}_{2}$ /alkane studied (i.e. for all 244 experimental data points), show that the PSRK is the method that best predicts the equilibrium data for these systems $\left(\varepsilon_{\text {PSRK }}=0.016\right)$, and the WS mixing rule is the one that gives the worst results $\left(\varepsilon_{\mathrm{WS}}=0.029\right)$, having the LCVM an intermediate quality $\left(\varepsilon_{\mathrm{LCVM}}=0.024\right)$.

\section{Systems $\mathrm{CO}_{2} /$ alcohol}

The prediction of phase equilibria for the systems $\mathrm{CO}_{2}$ /alcohol by the PSRK and LCVM models with the parameters published in the literature $[20,25,30]$ gives rise to a mean quadratic deviations of 0.076 and 0.085 , respectively. Since these values are slightly high, it was attempted the calculation of new interaction parameters for these models using the same data bank used to obtain the parameters for the WS mixing rule. This data bank has 257 experimental data points, covering temperatures from 288 to $395 \mathrm{~K}$, pressures from 0.5 until $19.0 \mathrm{MPa}$, and contains alcohols with a maximum of eight carbon atoms.

The calculated and revised interaction parameters between the groups $\mathrm{CO}_{2} / \mathrm{OH}$ are given in Tables 1-3, for the WS, PSRK and LCVM mixing rules, respectively. Fig. 2 shows the prediction for the solubility of ethanol, iso-butanol and iso-pentanol in $\mathrm{CO}_{2}$, according to the PSRK, LCVM and WS mixing rules. As it would be expected, due to the polarity of these compounds, the predictions are worse than for the alkane systems. The PSRK and LCVM models give identical results $\left(\varepsilon_{\mathrm{PSRK}}=0.055, \varepsilon_{\mathrm{LCVM}}=0.053\right)$, which

Table 3

Revised and calculated $^{(*)}$ interaction parameters for the LCVM mixing rule

\begin{tabular}{lrrlr}
\hline Group k/group m & $A_{\mathrm{km}}(\mathrm{K})$ & $A_{\mathrm{mk}}(\mathrm{K})$ & $B_{\mathrm{km}}$ & \multicolumn{1}{l}{$B_{\mathrm{mk}}$} \\
\hline $\mathrm{CO}_{2} / \mathrm{OH}$ & 87.100 & 943.660 & 1.96365 & 2.58830 \\
$\mathrm{CO}_{2} / \mathrm{CHO}^{(*)}$ & -110.933 & 6.972 & 8.2838 & -8.1331 \\
\hline
\end{tabular}


are much better than the predictions obtained with the WS mixing rule $\left(\varepsilon_{\mathrm{WS}}=0.111\right)$.

The improvement obtained for the PSRK and LCVM models with the revised parameters calculated in this study is shown in Fig. 3, for the systems $\mathrm{CO}_{2}$ /ethanol and $\mathrm{CO}_{2}$ /iso-butanol, where the predictions with the parameters published earlier in the literature and with the revised parameters proposed in this study are compared. It can be seen that the revised parameters improve slightly the predicted results.

\section{Systems $\mathrm{CO}_{2}$ /ester}

The interaction parameters between the groups $\mathrm{CO}_{2} / \mathrm{CCOO}$ for the WS mixing rule are given in

$\mathrm{CO}_{2} /$ Methylacetate

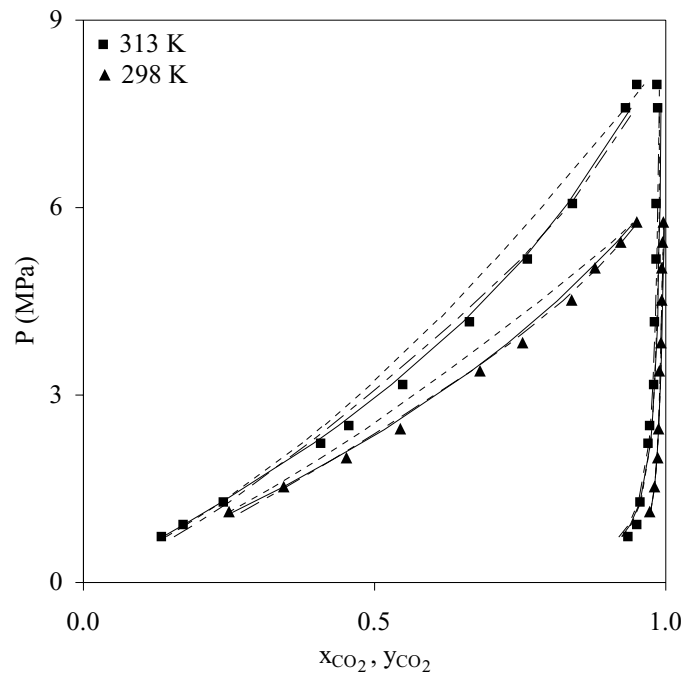

$\mathrm{CO}_{2}$ / Ethyl acetate

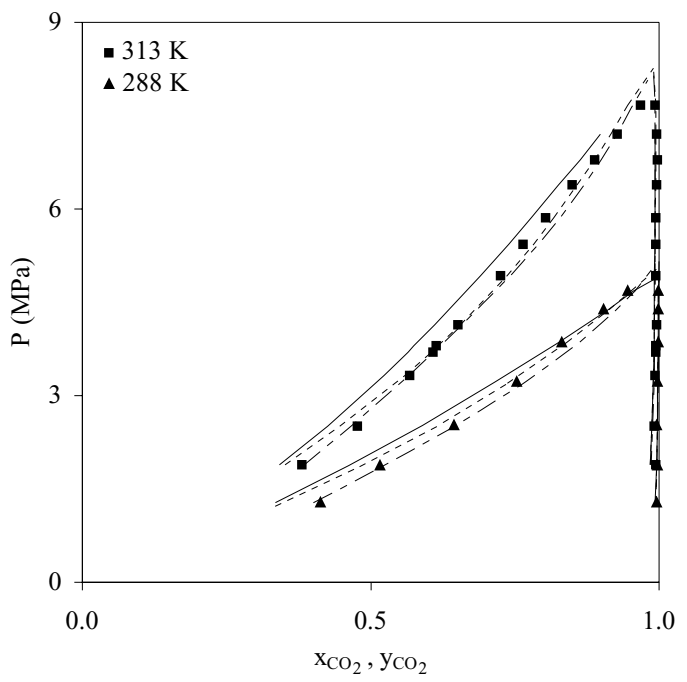

$\mathrm{CO}_{2}$ / Isoamyl acetate

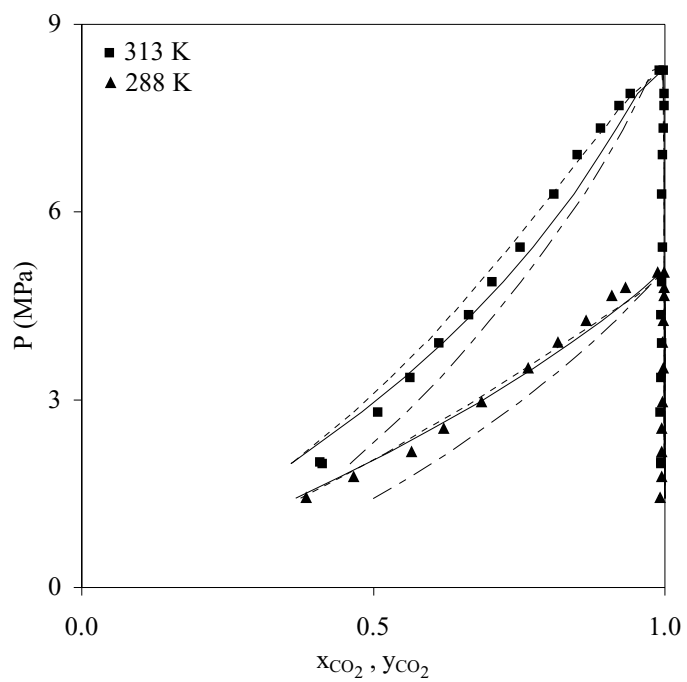

Fig. 4. PSRK (-), LCVM (---) and WS (---) predictions for systems $\mathrm{CO}_{2} /$ ester. 
$\mathrm{CO}_{2} /$ Butanal

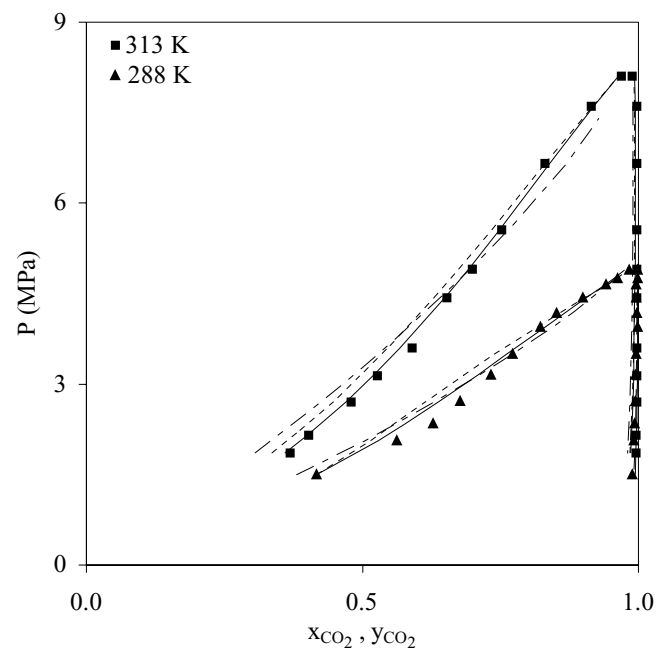

$\mathrm{CO}_{2} /$ Decanal

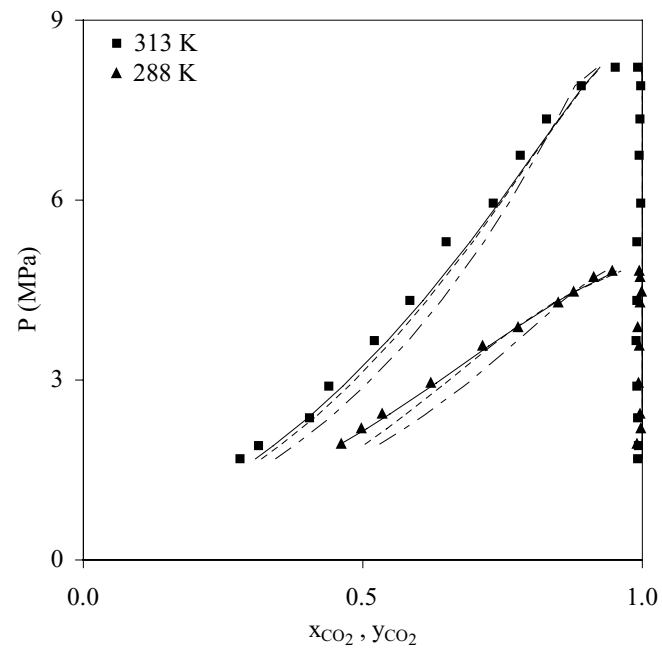

Fig. 5. PSRK (-), LCVM (---) and WS (---) predictions for systems $\mathrm{CO}_{2}$ /aldehyde.

Table 1, and were obtained by fitting 238 experimental data points, for a temperature range of $288-323 \mathrm{~K}$, pressures between 1.1 and $9.2 \mathrm{MPa}$, and for esters having between 3 and 7 carbon atoms.

In Fig. 4, the predictions by the PSRK, LCVM and WS mixing rules are compared with the ex- perimental data for some $\mathrm{CO}_{2} /$ esters systems (i.e. $\mathrm{CO}_{2} /$ methyl acetate, $\mathrm{CO}_{2} /$ ethyl acetate and $\mathrm{CO}_{2}$ /isoamyl acetate). Analyzing the mean quadratic deviations for these systems ( $\varepsilon_{\mathrm{PSRK}}=0.035$, $\left.\varepsilon_{\mathrm{LCVM}}=0.047, \varepsilon_{\mathrm{WS}}=0.035\right)$, it is verified that the PSRK and WS models predict equally well the phase
$\mathrm{CO}_{2} /$ Butanal

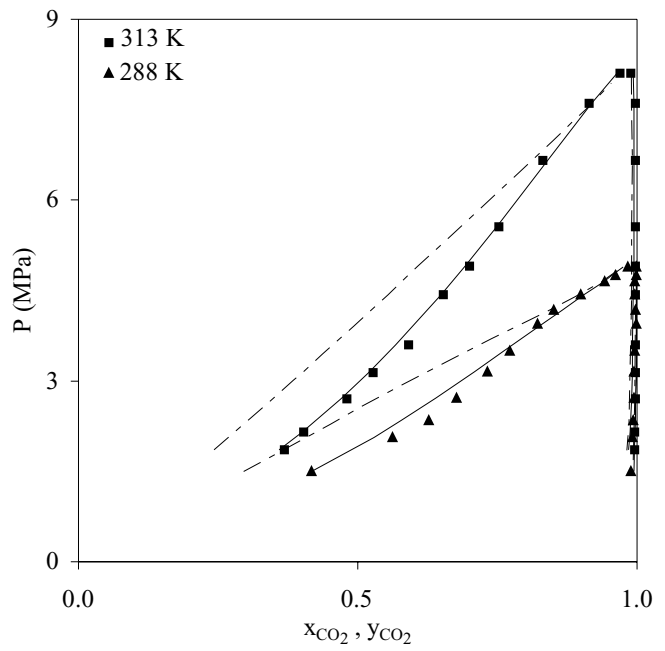

$\mathrm{CO}_{2} /$ Decanal

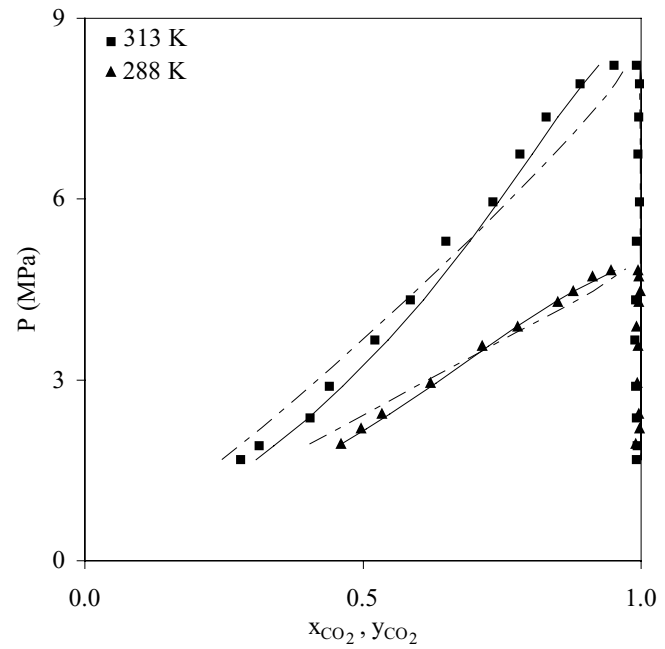

Fig. 6. Comparison between the results obtained with the published (---) and the revised (-) interaction parameters for the groups $\mathrm{CO}_{2} / \mathrm{CHO}$. 
equilibria, giving the LCVM model slightly worse results.

\section{Systems $\mathrm{CO}_{2}$ /aldehyde}

As for the systems containing alcohols, it was found that the existing parameters for the PSRK model [25] gave poor phase equilibria predictions for the $\mathrm{CO}_{2} /$ aldehyde systems $(\varepsilon$ PSRK $=0.056)$, which led to the calculation of a new set of interaction parameters for the groups $\mathrm{CO}_{2} / \mathrm{CHO}$ in an attempt to improve the quality of the predicted results. A data bank with 68 experimental points, covering a temperature range of $288-313 \mathrm{~K}$, pressures between 1.5 and $8.2 \mathrm{MPa}$, and having aldehydes with 4 and 10 carbon atoms was used to obtain the revised parameters for the PSRK model, and to calculate the parameters for the LCVM and WS mixing rules. These parameters are given in Tables 1-3 for the WS, PSRK and LCVM models, respectively.

In Fig. 5, the experimental data is compared with the predictions by the PSRK (with the revised parameters), LCVM and WS mixing rules. Once again, the WS model is the one that gives the worst results $\left(\varepsilon_{\mathrm{WS}}=\right.$ 0.034), giving the PSRK and LCVM models almost identical results $\left(\varepsilon_{\mathrm{PSRK}}=0.016, \varepsilon_{\mathrm{LCVM}}=0.023\right)$. The improvement gained with the revised parameters proposed for the PSRK model can be seen in Fig. 6, where the predictions for the systems $\mathrm{CO}_{2} /$ butanal and $\mathrm{CO}_{2} /$ decanal with the published and revised parameters are compared. This comparison shows a clear improvement obtained with the use of the revised parameters.

\section{Conclusions}

In this work, the PSRK, LCVM and WS mixing rules, associated with the UNIFAC group contribution model to calculate the excess Gibbs free energy, are compared as to their capability for predicting the phase equilibria of binary systems containing carbon dioxide and compounds belonging to the main families of the aromatic compounds of wine. Since for the WS mixing rule there are no interaction parameters published for the group $\mathrm{CO}_{2}$, the interaction parameters between the groups $\mathrm{CO}_{2} / \mathrm{CH}_{2}$,
$\mathrm{CO}_{2} / \mathrm{OH}, \mathrm{CO}_{2} / \mathrm{CHO}$ and $\mathrm{CO}_{2} / \mathrm{CCOO}$ were determined. For the LCVM mixing rule, the interaction parameters between the groups $\mathrm{CO}_{2} / \mathrm{CHO}$ were also calculated, because there are no parameters in the literature for these groups.

An initial attempt to predict the phase equilibria for the systems $\mathrm{CO}_{2} /$ alcohol and $\mathrm{CO}_{2}$ /aldehyde with the PSRK model, and for the system $\mathrm{CO}_{2} /$ alcohol with the LCVM mixing rule, gave rise to significant errors. Therefore, the published parameters for these systems were revised and new values were proposed.

The results obtained with these three mixing rules for the systems $\mathrm{CO}_{2}$ /alkane, $\mathrm{CO}_{2} /$ alcohol, $\mathrm{CO}_{2}$ /ester and $\mathrm{CO}_{2}$ /aldehyde show that the WS mixing rule is the method that gives worse results, ex-

Table A.1

Critical properties and acentric factor for pure components

\begin{tabular}{|c|c|c|c|c|}
\hline & $T_{\mathrm{c}}(\mathrm{K})$ & $P_{\mathrm{c}}(\mathrm{MPa})$ & $\omega$ & Reference \\
\hline \multicolumn{5}{|l|}{ Inorganic compounds } \\
\hline $\mathrm{CO}_{2}$ & 304.2 & 7.39 & 0.239 & [39] \\
\hline \multicolumn{5}{|l|}{ Alkanes } \\
\hline Propane & 369.8 & 4.25 & 0.154 & {$[32]$} \\
\hline Butane & 425.2 & 3.80 & 0.201 & [32] \\
\hline iso-Butane & 408.1 & 3.65 & 0.176 & [40] \\
\hline Pentane & 469.7 & 3.36 & 0.251 & {$[32]$} \\
\hline iso-Pentane & 460.4 & 3.38 & 0.227 & {$[40]$} \\
\hline Hexane & 507.3 & 3.01 & 0.301 & {$[32]$} \\
\hline Heptane & 540.1 & 2.74 & 0.350 & {$[32]$} \\
\hline Decane & 617.5 & 2.10 & 0.491 & {$[32]$} \\
\hline \multicolumn{5}{|l|}{ Alcohols } \\
\hline Ethanol & 513.9 & 6.15 & 0.644 & {$[32]$} \\
\hline 1-Propanol & 536.7 & 5.17 & 0.620 & [32] \\
\hline 2-Propanol & 508.4 & 4.76 & 0.664 & {$[32]$} \\
\hline 1-Butanol & 563.0 & 4.41 & 0.590 & {$[32]$} \\
\hline iso-Butanol & 547.7 & 4.30 & 0.588 & [40] \\
\hline 1-Pentanol & 588.2 & 3.91 & 0.578 & {$[32]$} \\
\hline iso-Pentanol & 579.5 & 3.85 & 0.580 & {$[40]$} \\
\hline 1-Octanol & 684.8 & 2.86 & 0.324 & {$[32]$} \\
\hline \multicolumn{5}{|l|}{ Esters } \\
\hline Methyl acetate & 506.8 & 4.69 & 0.254 & {$[40]$} \\
\hline Ethyl acetate & 524.1 & 3.85 & 0.362 & [39] \\
\hline Propyl acetate & 549.4 & 3.33 & 0.392 & {$[40]$} \\
\hline Isoamyl acetate & 599.2 & 2.82 & 0.408 & [41] \\
\hline Ethyl propionate & 546.0 & 3.36 & 0.395 & {$[40]$} \\
\hline \multicolumn{5}{|l|}{ Aldehydes } \\
\hline Butanal & 545.4 & 5.38 & 0.352 & [39] \\
\hline Decanal & 652.0 & 2.26 & 0.634 & [39] \\
\hline
\end{tabular}


cept for the system $\mathrm{CO}_{2}$ /propane at high pressures and temperatures, and the systems $\mathrm{CO}_{2}$ /ester, for which the errors are identical to those of the PSRK. This is not a surprising result, because, even though the WS mixing rule has the advantage of being consistent with the quadratic dependence on composition of the second virial coefficient, it is well known that this mixing rule fails for polar and asymmetric systems, as is the case for most of the systems studied. To make this method completely predictive the binary interaction parameter $k_{12}$ (Eq. (21)) had to be estimated for fixed values of temperature and composition, which restricts the applicability of the model. Therefore, it may be expected that the molecular version of the
WS mixing rule would give better results for these systems.

The PSRK and LCVM mixing rules give similar results, although the PSRK model is the one that best predicts the phase equilibria for the systems studied, with a quadratic mean deviation always lower than 5.5\%. The improvement in the prediction obtained with the revised parameters for the PSRK and LCVM models is only slight for the systems $\mathrm{CO}_{2} /$ alcohol, but significant for the systems $\mathrm{CO}_{2}$ /aldehyde.

The lack of reliable experimental data for multicomponent mixtures is, at present, an obstacle to the extension of this analysis to mixtures of industrial interest.

Table A.2

Mathias-Copeman constants $\left(C_{1}, C_{2}\right.$ and $\left.C_{3}\right)$ for the SRK and PR-EOS, and $m_{1}$ parameter for the PRSV-EOS

\begin{tabular}{|c|c|c|c|c|c|c|c|}
\hline & \multicolumn{3}{|c|}{ SRK-EOS } & \multicolumn{3}{|c|}{ PR-EOS } & \multirow{2}{*}{$\frac{\text { PRSV-EOS }}{m_{1}}$} \\
\hline & $C_{1}$ & $C_{2}$ & $C_{3}$ & $C_{1}$ & $C_{2}$ & $C_{3}$ & \\
\hline \multicolumn{8}{|l|}{ Inorganic compounds } \\
\hline $\mathrm{CO}_{2}$ & 0.5984 & 2.3820 & 0.0316 & 0.4633 & 2.4202 & 0.0838 & $0.0429^{*}$ \\
\hline \multicolumn{8}{|l|}{ Alkanes } \\
\hline Propane & 0.7250 & -0.0678 & 0.0365 & 0.5923 & 0.0577 & 0.0362 & $0.0314[32]$ \\
\hline Butane & 0.7820 & 0.0097 & 0.0000 & 0.6668 & 0.0246 & 0.0190 & $0.0344[32]$ \\
\hline iso-Butane & 0.7630 & -0.0168 & -0.0071 & 0.6509 & -0.0085 & 0.0000 & $0.1701^{*}$ \\
\hline Pentane & 0.8612 & -0.0078 & 0.0000 & 0.7425 & -0.0182 & 0.1093 & $0.0395[32]$ \\
\hline iso-Pentane & 0.8287 & -0.0141 & 0.0000 & 0.6605 & 0.2740 & -0.0055 & $0.0697^{*}$ \\
\hline Hexane & 0.9406 & -0.0319 & -0.0170 & 0.8067 & 0.0318 & 0.0000 & $0.0510[32]$ \\
\hline Heptane & 1.0072 & 0.0059 & 0.0000 & 0.8777 & 0.0194 & -0.0053 & $0.0465[32]$ \\
\hline Decane & 1.2123 & 0.0084 & 0.0000 & 1.0688 & 0.0126 & 0.0310 & $0.0451[32]$ \\
\hline \multicolumn{8}{|l|}{ Alcohols } \\
\hline Ethanol & 1.4401 & -0.1044 & -0.0179 & 1.2788 & -0.0067 & -0.1009 & $-0.0337[32]$ \\
\hline 1-Propanol & 1.3600 & 0.1917 & 0.0596 & 1.2075 & 0.2326 & 0.0409 & $0.2142[32]$ \\
\hline 2-Propanol & 1.4173 & 0.1903 & 0.0076 & 1.2392 & 0.3356 & 0.1512 & $0.2326[32]$ \\
\hline 1-Butanol & 1.2356 & 0.6834 & 0.0790 & 1.0532 & 0.8950 & 0.1475 & $0.3343[32]$ \\
\hline iso-Butanol & 1.2690 & 0.4701 & 0.1897 & 1.0578 & 0.8310 & 0.3845 & $0.2742^{*}$ \\
\hline 1-Pentanol & 1.2440 & 0.5000 & 0.1000 & 1.0995 & 0.5000 & 0.1000 & $0.3678[32]$ \\
\hline iso-Pentanol & 1.1896 & 0.7203 & 0.0613 & 1.0049 & 0.9686 & 0.0666 & $0.3568^{*}$ \\
\hline 1-Octanol & 0.6592 & 1.9410 & 0.0500 & 0.5424 & 1.8863 & 0.0500 & $0.8294[32]$ \\
\hline \multicolumn{8}{|l|}{ Esters } \\
\hline Methyl acetate & 0.9693 & -0.0092 & 0.0000 & 0.8378 & 0.0351 & 0.0470 & $0.4560^{*}$ \\
\hline Ethyl acetate & 1.0159 & 0.0093 & 0.0000 & 0.8908 & 0.0002 & 0.0395 & $0.0228^{*}$ \\
\hline Propyl acetate & 1.0612 & 0.0151 & 0.0859 & 0.9077 & 0.1640 & 0.0239 & $0.7134^{*}$ \\
\hline Isoamyl acetate & 0.9316 & 0.5451 & 0.0560 & 0.7856 & 0.6663 & 0.0253 & $0.0592^{*}$ \\
\hline Ethyl propionate & 1.0655 & 0.0100 & 0.0010 & 0.9202 & 0.1000 & 0.0019 & $0.0278^{*}$ \\
\hline \multicolumn{8}{|l|}{ Aldehydes } \\
\hline Butanal & 0.9170 & 0.0100 & 0.0000 & 0.8002 & 0.0060 & 0.0000 & $-0.4348^{*}$ \\
\hline Decanal & 1.4344 & 0.0064 & 0.1049 & 1.2699 & 0.0536 & 0.2130 & $0.1822^{*}$ \\
\hline
\end{tabular}

* Value obtained in this work. 


\section{Acknowledgements}

The authors would like to acknowledge the financial support provided by the Fundação para a Ciência e Tecnologia (project PRAXIS XXI BD/9729/96) and by the Centro de Biotecnologia e Química Fina, and the facilities conceded by the Faculdade de Engenharia da Universidade do Porto.

\section{Appendix A. Pure component properties}

In this appendix the pure component properties needed for the implementation of the PSRK, LCVM and WS mixing rules are summarized. The critical properties and acentric factor are given in Table A.1. The Mathias-Copeman constants (for the SRK-EOS and PR-EOS) and the parameter $m_{1}$ of

Table B.1

Area $\left(Q_{\mathrm{k}}\right)$ and volume $\left(R_{\mathrm{k}}\right)$ parameters for the original UNIFAC model [27]

\begin{tabular}{lllll}
\hline $\begin{array}{l}\text { Group } \\
\text { number }\end{array}$ & Group & Sub-group & $R_{\mathrm{k}}$ & $Q_{\mathrm{k}}$ \\
\hline 1 & $\mathrm{CH}_{2}$ & $\mathrm{CH}_{3}$ & 0.9011 & 0.848 \\
& & $\mathrm{CH}_{2}$ & 0.6744 & 0.540 \\
& & $\mathrm{CH}$ & 0.4469 & 0.228 \\
& & $\mathrm{C}$ & 0.2195 & 0.000 \\
5 & $\mathrm{OH}$ & $\mathrm{OH}$ & 1.0000 & 1.200 \\
10 & $\mathrm{CHO}$ & $\mathrm{CHO}$ & 0.9980 & 0.948 \\
11 & $\mathrm{CCOO}$ & $\mathrm{CH}_{3} \mathrm{COO}$ & 1.9031 & 1.728 \\
& & $\mathrm{CH}_{2} \mathrm{COO}$ & 1.6764 & 1.420 \\
56 & $\mathrm{CO}_{2}$ & $\mathrm{CO}_{2}$ & $1.3000[20]^{*}$ & $0.982[20]^{*}$ \\
& & & $1.296[30]^{* *}$ & $1.261[30]^{* *}$ \\
\hline
\end{tabular}

* Value used in the PSRK model.

** Value used in the LCVM model.
Table B.3

Group interaction parameters for the LCVM mixing rule [26,30]

\begin{tabular}{llrlrc}
\hline $\begin{array}{l}\text { Group } \\
\mathrm{k}\end{array}$ & $\begin{array}{l}\text { Group } \\
\mathrm{m}\end{array}$ & $\begin{array}{l}A_{\mathrm{km}} \\
(\mathrm{K})\end{array}$ & $\begin{array}{l}A_{\mathrm{mk}} \\
(\mathrm{K})\end{array}$ & \multicolumn{1}{l}{$B_{\mathrm{km}}$} & $B_{\mathrm{mk}}$ \\
\hline $\mathrm{CO}_{2}$ & $\mathrm{CH}$ & 110.6 & 116.7 & 0.5003 & -0.9106 \\
$\mathrm{CO}_{2}$ & $\mathrm{OH}$ & 87.1 & 471.8 & 3.9270 & 2.588 \\
$\mathrm{CO}_{2}$ & $\mathrm{CCOO}$ & -126.9 & 102.75 & -1.8187 & -0.4999 \\
$\mathrm{CH}_{2}$ & OH & 986.5 & 156.4 & 0 & 0 \\
$\mathrm{CH}_{2}$ & $\mathrm{CHO}$ & 677.0 & 505.7 & 0 & 0 \\
$\mathrm{CH}_{2}$ & $\mathrm{CCOO}$ & 232.1 & 114.8 & 0 & 0 \\
\hline
\end{tabular}

the PRSV-EOS are presented in Table A.2. These values were obtained by fitting the respective EOS to vapor pressure data for the pure components. The references for the vapor pressure data used in the fitting procedure are given by Vázquez Silva [38]. The parameter $m_{1}$ was only calculated if its value was not available in the literature.

\section{Appendix B. UNIFAC parameters}

The excess Gibbs free energy $\left(G^{\mathrm{E}}\right)$ for the PSRK and LCVM models was calculated by the original UNIFAC method, with different expressions for the temperature dependence of the UNIFAC interaction parameter, $\Psi$, given by Eqs. (9) and (15), respectively. The group and sub-group interaction parameters for the original UNIFAC method are presented in Table B.1, and the published interaction parameters of interest are summarized in Tables B.2 and B.3, for the PSRK and LCVM models, respectively. For the LCVM mixing rule, the parameters for the group $\mathrm{CO}_{2}$ published by Voutsas et al. [30] were used (i.e. $R_{\mathrm{k}}=1.296$ and $\left.Q_{\mathrm{k}}=1.261\right)$.

For the WS mixing rule, the $G^{\mathrm{E}}$ was obtained by the modified UNIFAC method, whose group and

Table B.2

Group interaction parameters for the PSRK mixing rule [20,25,26]

\begin{tabular}{llcclccc}
\hline Group k & Group $\mathrm{m}$ & $A_{\mathrm{km}}(\mathrm{K})$ & $A_{\mathrm{mk}}(\mathrm{K})$ & $B_{\mathrm{km}}$ & $B_{\mathrm{mk}}$ & $C_{\mathrm{km}}\left(\mathrm{K}^{-1}\right)$ & $C_{\mathrm{mk}}\left(\mathrm{K}^{-1}\right)$ \\
\hline $\mathrm{CO}_{2}$ & $\mathrm{CH}$ & -38.672 & 919.8 & 0.8615 & -3.913 & $-1.791 \times 10^{-3}$ & $4.631 \times 10^{-3}$ \\
$\mathrm{CO}_{2}$ & $\mathrm{OH}$ & 148.2 & 510.6 & 0 & 0 & 0 & 0 \\
$\mathrm{CO}_{2}$ & $\mathrm{CHO}$ & 340.0 & -162.0 & 0 & 0 & 0 & 0 \\
$\mathrm{CO}_{2}$ & $\mathrm{CCOO}$ & -742.2 & 818.72 & 2.9173 & -3.5627 & 0 & 0 \\
$\mathrm{CH}_{2}$ & OH & 986.5 & 156.4 & 0 & 0 & 0 & 0 \\
$\mathrm{CH}_{2}$ & $\mathrm{CHO}$ & 677.0 & 505.7 & 0 & 0 & 0 & 0 \\
$\mathrm{CH}_{2}$ & $\mathrm{CCOO}$ & 232.1 & 114.8 & 0 & 0 & 0 & 0 \\
\hline
\end{tabular}


Table B.4

Area $\left(Q_{\mathrm{k}}\right)$ and volume $\left(R_{\mathrm{k}}\right)$ parameters for the modified UNIFAC model [33]

\begin{tabular}{lllll}
\hline $\begin{array}{l}\text { Group } \\
\text { number }\end{array}$ & Group & Sub-group & $R_{\mathrm{k}}$ & $Q_{\mathrm{k}}$ \\
\hline 1 & $\mathrm{CH}_{2}$ & $\mathrm{CH}_{3}$ & 0.6325 & 1.0608 \\
& & $\mathrm{CH}_{2}$ & 0.6325 & 0.7081 \\
& & $\mathrm{CH}$ & 0.6325 & 0.3554 \\
5 & $\mathrm{OH}$ & $\mathrm{OH}(\mathrm{p})$ & 1.2302 & 0.8927 \\
& & $\mathrm{OH}(\mathrm{s})$ & 1.0630 & 0.8663 \\
10 & $\mathrm{CHO}$ & $\mathrm{CHO}$ & 0.7173 & 0.7710 \\
11 & $\mathrm{CCOO}$ & $\mathrm{CH}_{3} \mathrm{COO}$ & 1.270 & 1.6286 \\
& & $\mathrm{CH}_{2} \mathrm{COO}$ & 1.270 & 1.4228 \\
56 & $\mathrm{CO}_{2}$ & $\mathrm{CO}_{2}$ & $1.296[30]$ & $1.261[30]$ \\
\hline
\end{tabular}

sub-group parameters used in this work are summarized in Table B.4.

\section{Appendix C. Experimental data}

In Table C. 1 is given a compilation of the bibliographic references for the experimental data used in

Table C. 1

Experimental data for the systems $\mathrm{CO}_{2}+\mathrm{X}$ used in this work

\begin{tabular}{|c|c|c|c|}
\hline$X$ & $T(\mathrm{~K})$ & $P(\mathrm{MPa})$ & Reference \\
\hline Propane & 244-344 & $0.5-6.6$ & {$[42,43]$} \\
\hline Butane & $278-387$ & $0.03-8.1$ & [44-46] \\
\hline iso-Butane & $311-369$ & $0.7-6.6$ & {$[47,48]$} \\
\hline Pentane & $273-438$ & $0.3-6.9$ & {$[49,50]$} \\
\hline iso-Pentane & $278-408$ & $0.15-8.2$ & {$[50,51]$} \\
\hline Hexane & $303-393$ & $0.9-11.6$ & {$[52,53]$} \\
\hline Heptane & $352-394$ & $0.4-13.3$ & {$[54]$} \\
\hline Decane & $378-511$ & $1.4-17.2$ & {$[55]$} \\
\hline Methyl acetate & $298-313$ & $1.1-8.0$ & {$[56]$} \\
\hline Ethyl acetate & $288-313$ & $1.3-7.7$ & [57] \\
\hline Propyl acetate & $303-323$ & $2.1-9.2$ & {$[58]$} \\
\hline Isoamyl acetate & $288-313$ & $1.4-8.3$ & {$[57]$} \\
\hline Ethyl propionate & $303-323$ & $1.7-9.1$ & [59] \\
\hline Ethanol & $304-333$ & $0.5-10.6$ & {$[60,61]$} \\
\hline 1-Propanol & $313-333$ & $0.5-10.8$ & {$[60]$} \\
\hline 2-Propanol & $335-395$ & $1.4-12.4$ & {$[62]$} \\
\hline 1-Butanol & $313-333$ & $0.5-11.2$ & {$[63]$} \\
\hline iso-Butanol & $288-328$ & $0.5-9.9$ & {$[63,64]$} \\
\hline 1-Pentanol & $315-337$ & $5.2-12.0$ & {$[65]$} \\
\hline iso-Pentanol & $288-313$ & $1.2-8.1$ & {$[64]$} \\
\hline 1-Octanol & $313-348$ & $4.0-19.0$ & {$[66]$} \\
\hline Butanal & $288-313$ & $1.5-8.1$ & {$[57]$} \\
\hline Decanal & $288-313$ & $1.7-8.2$ & [67] \\
\hline
\end{tabular}

this work to obtain the necessary interaction parameters and to analyzed the predictive quality of the three models studied. For each system, the temperature and pressure range of the experimental data used is indicated.

\section{References}

[1] M. Ortega-Heras, M.L. González-San José, S. Beltrán, Aroma composition of wine studied by different extraction methods, Anal. Chim. Acta 458 (2002) 85.

[2] P. Schreier, Flavour composition of wines: a review, CRC Food Sci. Nutr. 12 (1979) 59.

[3] U. Schobinger, Nonalcoholic wine-manufacturing processes and sensory aspects, Mitt. Gebiete Lebensm. Hyg. 77 (1) (1986) 23.

[4] I. Medina, J.L. Martinez, Dealcoholization of cider by supercritical extraction with carbon dioxide, in: Proceedings of the 3rd International Symposium on Supercritical Fluids, vol. 2, 1994, p. 401.

[5] M. Perrut, M. Nunes da Ponte, Liquid-fluid fractionation: the extraction of aromas from fermented and distilled beverages, in: Proceedings of the 4th International Symposium on Supercritical Fluids, vol. C, 1997, p. 845.

[6] R. Bini, Tecnologia della dealcolazione e problemi organolettici conseguenti, La Rivista della Societá Italiana di Scienza dell'Alimentazione 13 (5) (1984) 425.

[7] B.H. Déglon, Procédé pour la séparation des alcools et essences volatiles des autres produits dans les mélanges obtenus par fermentations, Switzerland Patent 564603 (1975).

[8] H. Kieninger, J. Haimerl, Manufacture of alcohol-reduced beer by vacuum distillation, Brauwelt 121 (17) (1981) 574.

[9] R. Pérez, M.D. Salvador, R. Melero, M.I. Nadal, F. Gasque, Desalcoholización de vino mediante destilación en columna: Ensayos previos, Rev. Argoquim. Tecnol. Aliment. 29 (1) (1989) 124.

[10] G. Mehl, Process to remove alcohol from beer, brewers' yeast, wine, sparkling wines, or the like, German Patent 3507150 C2 (1986).

[11] A.R. Boucher, Reduced alcohol wine and its manufacture, US Patent 4570534 (1986).

[12] J. Regan, Production of alcohol-free and low alcohol beers by vacuum distillation and dialysis, Ferment 3-4 (1988) 235.

[13] P. Cuenat, D. Kobel, J. Crettenand, L'osmose inverse et l'œnologie, Bull. de L'O.I.V. 62-701 (1989) 519.

[14] K. Bui, R. Dick, G. Moulin, P. Glazy, A reverse osmosis for the production of low ethanol content wine, Am. J. Enol. Vitic. 37 (4) (1986) 297.

[15] H. Goldstein, C.L. Cronan, E. Chicoye, Preparation of low alcohol beverages byreverse osmosis, US Patent 4612196 (1986).

[16] G.W. Von Hodenberg, Production of alcoholfree beers using reverse osmosis, Brauwelt Int. 2 (1991) 145. 
[17] K. Wucherpfennig, Possibilités d'utilisation de processus membranaires dans l'industrie des boissons, Bull. de L'O.I.V. 53-589 (1980) 187.

[18] A. Wiesenberger, E. Kolb, R. Weisrock, K. Keding, Production of non-alcoholicwine, German Patent 3114648 A1 (1982).

[19] M.J. Huron, J. Vidal, New mixing rules in simple equation of state for representing vapour-liquid equilibria of strongly nonideal mixtures, Fluid Phase Equil. 3 (1979) 255.

[20] T. Holderbaum, J. Gmehling, PSRK: a group contribution equation of state based on UNIFAC, Fluid Phase Equil. 70 (1991) 251.

[21] C. Boukouvalas, N. Spiliotis, P. Coutsikos, N. Tzouvaras, D. Tassios, Prediction of vapor-liquid equilibrium with the LCVM model: a linear combination of the Vidal and Michelsen mixing rules coupled with the original UNIFAC and the t-mPR equation of state, Fluid Phase Equil. 92 (1994) 75.

[22] D.S.H. Wong, S.I. Sandler, A theoretically correct mixing rule for cubic equations of state, AIChE J. 38 (5) (1992) 671.

[23] P. Coutsikos, N.S. Kalospiros, D.P. Tassios, Capabilities and limitations of the Wong-Sandler mixing rules, Fluid Phase Equil. 108 (1995) 59.

[24] P.M. Mathias, T.W. Copeman, Extension of the PengRobinson equation of state to complex mixtures: evaluation of the various forms of the local composition concept, Fluid Phase Equil. 13 (1983) 91.

[25] K. Fisher, J. Gmehling, Further development, status and results of the PSRK method for the prediction of vapor-liquid equilibria using gas solubilities, Fluid Phase Equil. 121 (1996) 185.

[26] A. Fredenslund, J. Gmehling, P. Rasmussen, Vapor-Liquid Equilibria Using UNIFAC, Elsevier, Amsterdam, 1977.

[27] J. Gmehling, P. Rasmussen, Aa. Fredenslund, Vapor-liquid equilibria by UNIFAC group contribution: revision and extension-2, Ind. Eng. Chem. Process Des. Dev. 21 (1982) 118.

[28] J. Vidal, Mixing rules and excess properties in cubic equations of state, Chem. Eng. Sci. 33 (1978) 787.

[29] M.L. Michelsen, A modified Huron-Vidal mixing rule for cubic equation of state, Fluid Phase Equil. 60 (1990) 213.

[30] E.C. Voutsas, C.J. Boukouvalas, N.S. Kalospiros, D.P. Tassios, The performance of $\mathrm{EOS} / G^{\mathrm{E}}$ models in the prediction of vapor-liquid equilibria, Fluid Phase Equil. 116 (1996) 480.

[31] S.I. Sandler, Models for Thermodynamic and Phase Equilibria Calculations, Marcel Dekker, New York, 1994.

[32] R. Stryjek, J.H. Vera, PRSV: an improved Peng-Robinson equation of state for pure compounds and mixtures, Can. J. Chem. Eng. 64 (1986) 323.

[33] J. Gmehling, J. Li, M. Schiller, A modified UNIFAC model-2. Present parameter matrix and results for different thermodynamic properties, Ind. Eng. Chem. Res. 32 (1993) 178.

[34] B.L. Larsen, P. Rasmussen, A. Fredenslund, A modified UNIFAC group-contribution model for the prediction of phase equilibria and heats of mixing, Ind. Eng. Chem. Res. 26 (1987) 2274.
[35] U. Weidlich, J. Gmehling, A modified UNIFAC model-1. Prediction of VLE, $\mathrm{h}^{\mathrm{E}}$, and $\gamma^{\infty}$, Ind. Eng. Chem. Res. 26 (1987) 1372.

[36] M.A. Wolfe, Numerical Methods for Unconstrained Optimization: An Introduction, Van Nostrand Reinhold Co., New York, 1978.

[37] P.E. Gill, W. Murray, M.H. Wright, Practical Optimization, Academic Press, London, 1981.

[38] M. Vázquez Silva, Estudo do equilíbrio de fases de sistemas relevantes para o processo de desalcoolização de vinho por extracção supercrítica, $\mathrm{PhD}$ Thesis, Universidade do Porto, Faculdade de Engenharia, Portugal, 2002.

[39] C.L. Yaws, D. Chen, Y.C. Yang, L. Tan, D. Nico, Critical properties of chemicals, Hydrocarbon Procss. 68 (1989) 61.

[40] R.C. Reid, J.M. Prausnitz, T.K. Sherwood, The Properties of Gases and Liquids, third edition, McGraw-Hill, New York, 1977.

[41] K.H. Simmrock, R. Janowsky, A. Ohnsorge, Critical Data of Pure Substances, in: DECHEMA, Chemistry Data Series, II-1, 1986.

[42] S.E.M. Hamam, B.C.Y. Lu, Isothermal vapor-liquid equilibriums in binary system propane-carbon dioxide, J. Chem. Eng. Data 21 (2) (1976) 200.

[43] H.H. Reamer, B.H. Sage, W.N. Lacey, Phase equilibria in hydrocarbon systems: volumetric phase behavior of the propane-carbon dioxide system, Ind. Eng. Chem. 43 (11) (1951) 2515.

[44] M.E.P. Fernandez, J.A. Zollweg, W.B. Streett, Vapor-liquid equilibrium in the binary system carbon dioxide $+n$-butane, J. Chem. Eng. Data 34 (3) (1989) 324.

[45] J.J.C. Hsu, N. Nagarajan, R.L. Robinson Jr., Equilibrium phase compositions, phase densities, and interfacial tensions for $\mathrm{CO}_{2}+$ hydrocarbon systems. 1. $\mathrm{CO}_{2}+n$-butane, J. Chem. Eng. Data 30 (4) (1985) 485.

[46] H. Kalra, T.R. Krishnan, D.B. Robinson, Equilibrium phase properties of the carbon dioxide- $n$-butane and nitrogenhydrogen sulfide systems at sub-ambient temperatures, J. Chem. Eng. Data 21 (2) (1976) 222.

[47] G.J. Besserer, D.B. Robinson, Equilibrium phase properties of $i$-butane-carbon dioxide system, J. Chem. Eng. Data 18 (3) (1973) 298.

[48] L.A. Weber, Simple apparatus for vapor-liquid equilibrium measurements with the data for binary systems of carbon dioxide with $n$-butane and isobutane, J. Chem. Eng. Data 34 (2) (1989) 171.

[49] H. Cheng, M.E.P. Fernandez, J.A. Zollweg, W.B. Streett, Vapor-liquid equilibrium in the system carbon dioxide $+n$-pentane from 252 to $458 \mathrm{~K}$ at pressures up to $10 \mathrm{MPa}$, J. Chem. Eng. Data 34 (3) (1989) 319.

[50] A.D. Leu, D.B. Robinson, Equilibrium phase properties of selected carbon dioxide binary systems: $n$-pentane-carbon dioxide and isopentane-carbon dioxide, J. Chem. Eng. Data 32 (4) (1987) 447.

[51] G.J. Besserer, D.B. Robinson, Equilibrium-phase properties of isopentane-carbon dioxide system, J. Chem. Eng. Data 20 (1) (1975) 93. 
[52] Y.H. Li, K.H. Dillard, R.L. Robinson Jr., Vapor-liquid phase equilibrium for carbon dioxide- $n$-hexane at 40,80 and $120{ }^{\circ}$ C, J. Chem. Eng. Data 26 (1) (1981) 53.

[53] Z. Wagner, I. Wicheterle, High-pressure vapor-liquid equilibrium in systems containing carbon dioxide, 1-hexene and n-hexane, Fluid Phase Equil. 33 (1987) 109.

[54] H. Kalra, H. Kubota, D.B. Robinson, H.J. Ng, The equilibrium phase properties of the carbon dioxide- $n$-heptane system, J. Chem. Eng. Data 23 (4) (1978) 317.

[55] H.H. Reamer, B.H. Sage, Phase equilibria in hydrocarbon systems. Volumetric and phase behavior of the $n$-decane- $\mathrm{CO}_{2}$ system, J. Chem. Eng. Data 8 (4) (1963) 508.

[56] K. Ohgaki, T. Katayama, Isothermal vapor-liquid equilibriums for systems ethyl ether-carbon dioxide and methyl acetate-carbon dioxide at high pressures, J. Chem. Eng. Data 20 (3) (1975) 264.

[57] M. Vázquez Silva, D. Barbosa, The solubility of aromatic components of wine in supercritical carbon dioxide, in: Proceedings of the 8th Meeting on Supercritical Fluids, vol. 2, 2002, p. 913.

[58] Z. Wagner, Vapour-liquid equilibrium at high pressure in the system containing carbon dioxide and propyl acetate, Fluid Phase Equil. 110 (1995) 175.

[59] Z. Wagner, Vapour-liquid equilibrium in the carbon dioxideethyl propanoate system at pressures from 2 to $9 \mathrm{MPa}$ and temperatures from 303 to $323 \mathrm{~K}$, Fluid Phase Equil. 112 (1995) 125.
[60] K. Suzuki, H. Sue, M. Itou, R.L. Smith, H. Inomata, K. Arai, S. Saito, Isothermal vapor-liquid equilibrium data for binary systems at high pressures: $\mathrm{CO}_{2}+$ methanol, $\mathrm{CO}_{2}$ + ethanol, $\mathrm{CO}_{2}+1$-propanol, methanol + ethanol, methane + 1-propanol, ethane + ethanol, ethane + 1-propanol systems, J. Chem. Eng. Data 35 (1990) 63.

[61] S. Takishima, K. Saiki, K. Arai, Phase equilibria for $\mathrm{CO}_{2}-$ $\mathrm{C}_{2} \mathrm{H}_{5} \mathrm{OH}-\mathrm{H}_{2} \mathrm{O}$ system, J. Chem. Eng. Jpn. 19 (1) (1986) 48.

[62] M. Radosz, Vapor-liquid equilibrium for 2-propanol and carbon dioxide, J. Chem. Eng. Data 31 (1986) 43.

[63] Y. Zhi, S. Meirin, S. Jun, High pressure vapor-liquid phase equilibrium for carbon dioxide- $n$-butanol and carbon dioxideiso-butanol, J. Fuel Chem. Technol. 24 (1) (1996) 87.

[64] M. Vázquez Silva, D. Barbosa, High pressure vapor-liquid equilibrium data for the systems carbon dioxide/2-methyl1-propanol and carbon dioxide/3-methyl-1-butanol at 288.2, 303.2 and 313.2 K, Fluid Phase Equil. 198 (2) (2002) 229.

[65] D.W. Jennings, F. Chang, V. Bazaan, A.S. Teja, Vapor-liquid equilibria for carbon dioxide +1 -pentanol, J. Chem. Eng. Data 37 (1992) 337.

[66] W.L. Weng, M.J. Lee, Phase equilibrium measurements for the binary mixtures of 1-octanol plus $\mathrm{CO}_{2}, \mathrm{C}_{2} \mathrm{H}_{6}$ and $\mathrm{C}_{2} \mathrm{H}_{4}$, Fluid Phase Equil. 73 (1992) 117.

[67] M. Vázquez Silva, D. Barbosa, P. Ferreira, High pressure vapor-liquid equilibrium data for the system carbon dioxide + decanal at 288.2, 303.2, and 313.2 K, J. Chem. Eng. Data 47 (5) (2002) 1171. 